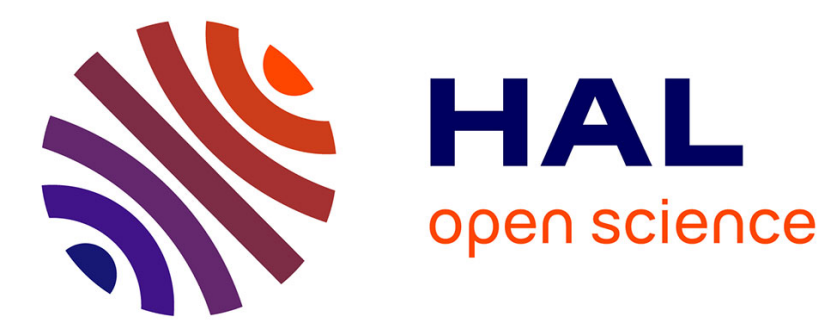

\title{
The Cloud Storage Ecosystem - A New Business Model for Internet Piracy?
}

Raymond Chan, Kam-Pui Chow, Vivien Chan, Michael Kwan

\section{To cite this version:}

Raymond Chan, Kam-Pui Chow, Vivien Chan, Michael Kwan. The Cloud Storage Ecosystem - A New Business Model for Internet Piracy?. 12th IFIP International Conference on Digital Forensics (DF), Jan 2016, New Delhi, India. pp.237-255, 10.1007/978-3-319-46279-0_12 . hal-01758684

\section{HAL Id: hal-01758684 \\ https://hal.inria.fr/hal-01758684}

Submitted on 4 Apr 2018

HAL is a multi-disciplinary open access archive for the deposit and dissemination of scientific research documents, whether they are published or not. The documents may come from teaching and research institutions in France or abroad, or from public or private research centers.
L'archive ouverte pluridisciplinaire HAL, est destinée au dépôt et à la diffusion de documents scientifiques de niveau recherche, publiés ou non, émanant des établissements d'enseignement et de recherche français ou étrangers, des laboratoires publics ou privés. 


\title{
Chapter 12
}

\section{THE CLOUD STORAGE ECOSYSTEM - A NEW BUSINESS MODEL FOR INTERNET PIRACY?}

\author{
Raymond Chan, Kam-Pui Chow, Vivien Chan and Michael Kwan
}

\begin{abstract}
Cloud storage, also known as "one-click file hosting," is the easiest method to share files. It enables users to upload any files without providing any information or installing any software. This chapter discusses the development of the cloud storage ecosystem before and after the Megaupload case of 2012. The roles and relationships of the key contributors in the cloud storage ecosystem are highlighted. Also, the manner in which the key contributors generate revenue is discussed and revenue estimates are provided based on Internet traffic data and domain information.
\end{abstract}

Keywords: Cloud storage ecosystem, file sharing, business model

\section{Introduction}

Cloud storage is widely used to share files that infringe copyright laws. Downloading files from cloud storage sites does not expose IP address information to parties other than the cloud storage provider. Hence, some cloud storage sites encourage users to upload and share files by paying them rewards [7]. To receive these rewards, cloud storage users upload their files to various public forums and encourage other users to download them. The greater the number of downloads from the shared links, the greater the income earned by the file uploaders. P2P file sharing networks do not have a financial reward component, which is why increasing numbers of users are sharing files using cloud storage.

In January 2012, the Megaupload cloud storage site was shut down by the United States in collaboration with New Zealand and Hong Kong [5]. It was estimated that Megaupload was making millions dollars in profits 
at the time. The charges against Megaupload included money laundering, racketeering and copyright infringement [13].

The Megaupload shutdown does not appear to have had a major impact on the cloud storage business. A 2014 report, Good Money Gone Bad, commissioned by the Digital Citizen Alliance [3], details how huge amounts of advertising revenue are earned by cloud storage sites as well as by other service providers (including P2P sites) that facilitate file sharing that involves copyright infringement. Clearly, increasing numbers of businesses - legal, dodgy and illegal - are leveraging cloud storage for their operations. However, it appears that there have been some observable changes in the cloud storage ecosystem after the 2012 Megaupload case. This chapter discusses the cloud storage ecosystem and the recent changes in the ecosystem. It highlights the roles and relationships of the key contributors in the ecosystem. Also, it discusses the manner in which key contributors generate income in the ecosystem and estimates their revenue using Internet traffic data and domain information.

\section{Cloud Storage Ecosystem}

Cloud storage or one-click file hosting provided by entities such as MEGA, Rapidshare and Mediafire offer rapid and convenient methods for uploading and sharing files. A user uploads a file to cloud storage and the cloud storage provider generates a uniform resource locator (URL) that contains meta-information about the shared file. The uploader then disseminates the URL to other users who are interested in downloading the file. Compared with earlier file sharing methods, such as FTP and P2P networks, cloud storage services provide tremendous availability, flexibility and anonymity to uploaders [1]. Moreover, file uploaders do not need to stay online in order to share files.

Uploading and Sharing Links. To upload a file, the file owner selects a cloud storage website. The website displays a file upload button to upload files. The user then chooses the file to upload and presses the upload button, upon which the file is submitted to the cloud storage site. The website then generates a unique download URL on the screen for the user to copy and share with others. A user who receives the URL can download the file directly. Some cloud storage sites also provide a URL to the uploader for deleting the file. Depending on the popularity of the file, the download URL and file are deleted after a certain period of time.

Ecosystem Changes. In 2011, Megaupload was ranked first in the top-ten list of file-sharing hosts, eight of them cloud storage sites [14]. 
This shows the popularity of cloud storage sites in 2011. According to Mahanti et al. [8], before the shutdown of Megaupload in 2012, the cloud storage ecosystem primarily comprised two major contributors: (i) file hosting cloud storage service providers; and (ii) linker sites providing search services to users. Mahanti et al. concluded that one of the drivers of file hosting service growth was the incentive schemes run by cloud storage providers such as Megaupload to attract uploaders to provide copyright-infringing content to increase traffic. This was also a key allegation against Megaupload in the 2012 U.S. Department of Justice indictment [5].

Following the indictment, Megaupload appears to have lost millions of users. One possibility is that the users moved to other file sharing technologies such as BitTorrent. Another is that they subscribed to other cloud storage sites. A piracy analysis study by Price [11] reports that the number of BitTorrent users increased 3.6\% in 2013 compared with 2011. On the other hand, the number of cloud storage users decreased $7.7 \%$ in 2013 compared with 2011, which appears to be a direct result of the Megaupload case.

Despite the downward trend in the use of cloud storage sites for file sharing soon after the Megaupload shutdown in 2012, cloud storage has become a huge market on the Internet with increasing profits. According to a 2014 report commissioned by Digital Citizens Alliance [4], the most profitable cloud storage site had annual profits of $\$ 17.6$ million. In order to increase cloud storage business, the cloud storage ecosystem reacted quickly to the law enforcement actions against Megaupload. The following trends have been observed:

- Change in Operation Mode: Ad-link shortening services now hide the original file download links. Also, social media platforms remove the ad-link shortening links that are shared by file uploaders on social media.

- Uploading to Multiple Sites: Since the file links at cloud storage sites expire after a period of time, it is now common practice for uploaders to upload files to multiple cloud storage sites so that, when a file link on one cloud storage system expires, a number of active links persist at other cloud storage sites. This resilience feature enables uploaders to continue to operate after cloud storage sites are shut down by law enforcement.

- Premium Downloading Without Subscriptions: According to a 2014 report by NetNames [4], a major portion of the income $(70 \%)$ of cloud storage sites comes from premium accounts. Indeed, premium account subscriptions are a proven gold mine for 


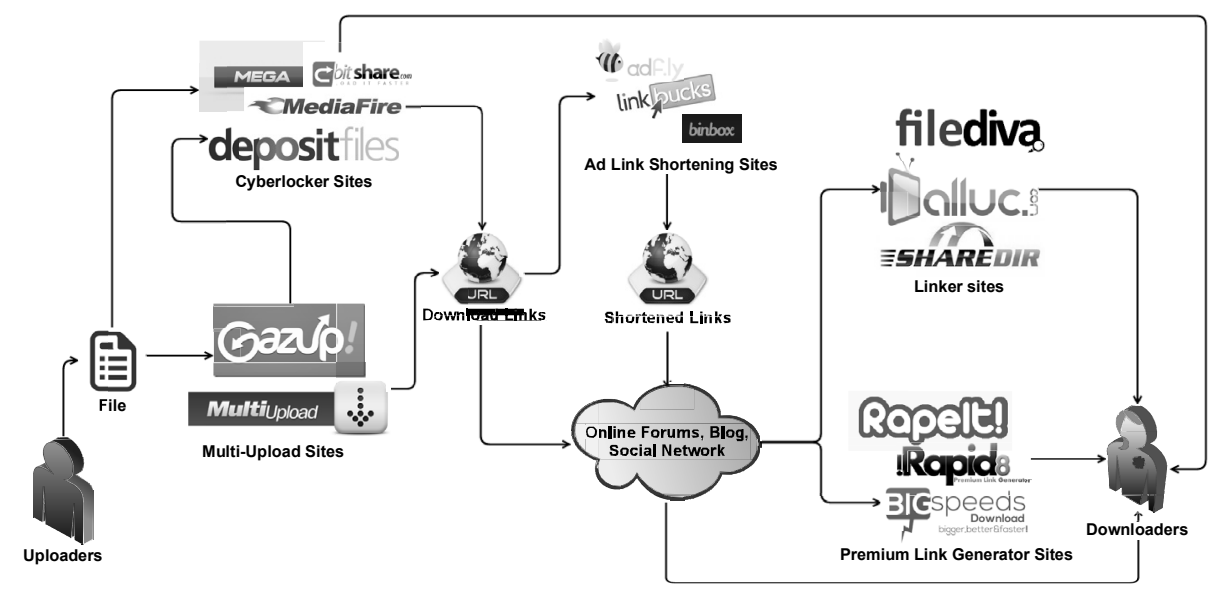

Figure 1. New cloud storage ecosystem.

cloud storage sites. In order to reap profits, premium link generator sites allow downloaders to enjoy premium services for free with no restrictions on downloading. The sites earn revenue from advertisers based on the number of premium users and/or their usage. The sites also provide resilient services to downloaders to enable them to operate after cloud storage sites are shut down by law enforcement.

The observations above indicate that the types of contributors in the cloud storage ecosystem have increased from two to five after the Megaupload case. The three new contributors to the ecosystem are: (i) ad-link shortening sites; (ii) multi-upload sites; and (iii) premium link generator sites. The entry of these new contributors appears to be a direct result of the Megaupload case.

Figure 1 presents the new cloud storage ecosystem. The major components of the ecosystem are:

- Leader/Central Contributor: The leader serves as a "hub" without which other ecosystem members would not be able to survive in the ecosystem [9].

- Cloud Storage Sites: These sites provide free or premium file hosting services to uploaders.

- Users: Users are important entities in the ecosystem. There would be no business ecosystem without users. There are two types of users: 
- Uploaders: These users actively provide content to cloud storage sites and publicize the content through various means.

- Downloaders: These users download content from cloud storage sites through various means.

- Contributors: These interdependent entities contribute to the growth of the business ecosystem and actively work on platforms provided by the ecosystem leader [9]. The contributor entities in a cloud storage ecosystem include:

- Linker Sites: These sites provide indexing services for downloaders to search for files hosted on cloud storage sites.

- Ad-Link Shortening Sites: These sites provide URL shortening and redirect services to convert cloud storage links before uploaders post them in public forums and blogs.

- Multi-Upload Sites: These sites provide services for uploaders to upload a given file to multiple cloud storage sites.

- Premium Link Generator Sites: These sites provide services for downloaders who do not wish to subscribe to premium accounts, but wish to download files without any restrictions.

\section{Related Work}

In September 2014, the Digital Citizens Alliance commissioned NetNames to study the revenue model of cloud storage providers. The study [4] estimated that the top-30 cloud storage sites had annual revenue amounting to $\$ 96.2$ million. Similarly, another report commissioned by Digital Citizens Alliance in February 2014 [3] noted that a huge amount of advertising income was generated by BitTorrent sites, linker sites, cloud storage sites and streaming sites. However, these reports only estimated the advertising income and subscription income generated by cloud storage sites and linker sites; they did not consider the multiplicative effect of the other contributors in the cloud storage ecosystem mentioned above.

Discussions of cloud storage revenue models usually focus on the advertising income and subscription income generated by cloud storage sites and linker sites [7]. However, the studies largely overlook the revenue generated by the entire cloud storage ecosystem. This chapter describes the revenue models of the five contributors described in the previous section. 


\section{Cloud Storage Ecosystem Revenue Model}

This section describes the dataset used in the study and the cloud storage ecosystem revenue model and its components.

\subsection{Dataset}

This study has drawn on data from a number of public sources. The selection of sites corresponding to the different contributors in the cloud storage ecosystem was based on the research team's knowledge and decade-long experience in digital forensics and Internet piracy.

- Web Traffic Data:

- Unique Page Views: This data was collected from Alexa Internet, a web traffic data analysis company owned by Amazon, that collects data on browsing behavior. The Alexa ranking is one of the most important indices of the browsing behavior of Internet users.

- Number of Unique Visitors: This data was collected from SiteWorthTraffic, an online web service that estimates website value. SiteWorthTraffic provides the unique page views of websites drawn from web traffic analysis sources.

\section{- Coud Storage Ecosystem Sites:}

- Leader/Central Contributor Sites: The top-ten cloud storage sites were selected based on the experience of frequent users of cloud storage sites.

\section{- Contributor Sites:}

* Linker Sites: The top-ten sites were selected based on results provided by search engines.

* Ad-Link Shortening Sites: The top-five sites were selected based on user input.

* Multi-Upload Sites: The top-ten sites were selected based on results provided by search engines.

* Premium Link Generator Sites: The top-ten sites were selected based on information in web forums and results provided by search engines.

\subsection{Leader/Central Contributor Revenue Model}

In general, cloud storage sites operate using the "freemium" business model [6], the most common Internet service business model. In this 
model, a service provider offers limited services free-of-charge and provides extra features and capacity for a fee. Numerous Internet services utilize cloud storage and provide a number of features to generate revenue. The current cloud storage ecosystem presented in Figure 1 shows that users share cloud storage files using various online services. This section provides details of the cloud storage business model and how services leverage cloud storage to generate revenue.

The two main mechanisms for generating revenue are advertisements and premium services:

- Advertisements: Advertisements are a major source of revenue for cloud storage sites. When a user browses a file to be downloaded, the website typically displays a number of advertisements on the screen. If the user does not have a premium account, the cloud storage site may require the user to wait for a few minutes (to check out the advertisements) before clicking the download button. Users are also encouraged to upload and share files; the greater the number of download URLs generated and published, the greater the likelihood that users will visit the download pages. Advertising companies place ads on cloud storage download pages frequented by large numbers of users. The Alexa ranking provides useful web traffic data that can be used to estimate advertising revenue. Based on the web traffic and daily page view information, it is possible to estimate the popularity of cloud storage sites and the average advertisement revenue, and to compute the monthly advertisement revenue generated by cloud storage sites. The current value of the cost per 1,000 impressions (CPM) is around $\$ 3$ [12]. In estimating the advertising revenue, a cloud storage site is assumed to join one advertisement service and one advertisement banner is displayed on each download page. Thus, the advertising service will pay the site $\$ 3$ per $1,000(=0.003)$ unique page views:

Monthly Ad Revenue $=0.003 \times$ Unique Page Views per Month

- Premium Accounts: Premium accounts are also a major source of revenue for cloud storage sites. Like Dropbox, Google Drive and Apple iCloud, cloud storage sites provide massive amounts of storage to users who register for premium accounts. Premium users also receive much more benefits and functionality than nonpaying users. These include more online storage, uploads of files of unlimited size and downloads of multiple files simultaneously, without speed limits and with the download links being preserved 
forever. Since advertising revenue depends on the popularity of a site and user activity, the revenue is unpredictable. Therefore, it is important for cloud storage sites to encourage users to sign up for premium services. This provides stable income while incentivizing premium users to keep using the services. According to SiteWorthTraffic, MEGA had 1,647,489 unique visitors per month and, as of July 2014, had one million registered users. Based on these statistics, the estimated number of registered users at a cloud storage site can be assumed to be $60.69 \%(=1,000,000 \div 1,647,489)$ of the unique visitors:

$$
\text { Registered Users }=0.6069 \times \text { Unique Visitors }
$$

In a news article [10], MEGA's Founder Kim Dotcom said that, in a freemium model, conversion rates of free users to paid users are in the range of $1 \%$ to $5 \%$. A cloud storage site provides free storage to registered users and provides more storage and faster download speeds if they pay a fee. Using the average free-to-paid user conversion rate of $3 \%(=0.03)$, the number of premium users is given by:

$$
\text { Premium Users }=0.03 \times \text { Registered Users }
$$

MEGA claimed to have one million registered users as of July 2014. Therefore, according to Equation (3), it had 30,000 paid users at that time. Based on MEGA's price schedule, these users would have paid MEGA between $\$ 352,393$ to $\$ 1,165,800$ per month.

\subsection{Contributor Revenue Models}

As mentioned above, there are four major contributors in a cloud storage ecosystem: (i) linker site; (ii) ad-link shortening site; (iii) multiupload site; and (iv) premium link generator site. The following are the revenue models of the four major contributors:

- Linker Sites: Typical cloud storage sites do not provide a file search feature. This new business opportunity is exploited by cloud storage indexing sites, also known as linker sites. Like web search engines, these sites index cloud storage links collected from web forums, blogs and social networks. They enable users to search for files, access file links and download the files without having to obtain the links from the file uploaders.

One of the largest linker sites is FileTube (www.filestube.com). It indexes files maintained at more than 60 cloud storage sites and 
encourages users to report new links to increase the size of the file link database. A "meta linker" site, Filediva (www.filediva. com), enables users to search for and retrieve files from multiple linker sites. Clearly, linker sites have significantly increased the popularity of cloud storage sites.

- Ad-Link Shortening Sites: Many file uploaders do not share their cloud storage links directly. Instead, they use an ad-link shortening service to convert (i.e., help hide) their actual cloud storage links before they post them on public forums and blogs. A file downloader needs to access a shortened link before accessing the real cloud storage download link. This enables the uploader to earn additional advertising income by sharing the shortened link. A popular URL shortening service is AdFly (adf.ly), which enables uploaders to earn $\$ 4$ per 1,000 clicks.

A similar service is provided by URL sharing sites that share files like cloud storage sites, but allow users to input any text content and generate links for sharing the content. Binbox (binbox.io) is a popular link sharing service, which enables registered users to earn $\$ 5$ per 1,000 clicks and to password-protect the links that are shared in web forums and social networks. URL sharing sites are becoming increasingly popular; they protect the content to be shared and can be used to disseminate secret messages. In many data leakage cases, hackers share passwords or email addresses using these services. Hence, uploaders not only earn income from pay-per-downloads provided by cloud storage sites, but also earn income from pay-per-clicks provided by ad-link shortening sites. Even if a user does not download a file completely, an uploader still earns revenue from the shortened link.

- Multi-Upload Sites: Multi-upload sites provide all-in-one uploading services. A file that is uploaded to a multi-upload site is automatically sent to multiple cloud storage sites. The download links from the various cloud storage sites are provided to the user to share the file. The multi-loading functionality enables file persistence - until all the file download links are removed, it is possible for users to access and download the file. An example is MultiUpload (multiupload.biz), which uploads a file to 21 cloud storage sites with just one click. As in the case of a linker site, a multi-upload site increases the content on a cloud storage site and increases the web traffic as well. 
- Premium Link Generator Sites: Premium link generator sites provide special services for users who do not wish to subscribe to premium accounts, but still desire to download files without any restrictions. These sites operate by purchasing and then using a number of premium accounts at many cloud storage sites. A user who wishes to download a file, copies and pastes the cloud storage file link at the premium link generator site. The premium link generator site downloads the file using its premium account and forwards the downloaded file to the user. As in the case of a proxy server, the speed of forwarding a file is faster than a free download from a cloud storage site.

Another approach is for a user to register a premium account with a premium link generator site. The user can then download files without speed restrictions from multiple cloud storage sites; the user saves money because it is not necessary to set up premium accounts at any of the cloud storage sites. Rapid8 (rapid8.com) is a popular premium link generator site, which enables users to obtain premium access to more than 45 cloud storage sites. Premium link generator sites earn revenue by displaying advisements and asking users to donate their premium accounts to provide better services.

\section{Results and Analysis}

This section summarizes the results based on traffic data collected in September 2014.

\subsection{Leader/Central Contributor Revenue}

In a 2012 press release [5], the U.S. Department of Justice asserted that Megaupload had about 150 million registered users and generated more than $\$ 175$ million in criminal proceeds. Approximately $\$ 150$ million came from premium users while the remaining $\$ 25$ million was online advertising revenue.

The fundamental question is how a cloud storage site can earn so much revenue. To answer this question, this research attempts to estimate the revenue earned by a cloud storage site based on web traffic popularity, advertisements and number of premium users. The number of premium users is estimated based on the number of unique visitors and the advertisement revenue is estimated from the number of unique page views. Finally, the monthly and annual revenue estimates of a cloud storage site are computed. 
Table 1. Ranks and unique page views/month for cloud storage sites.

\begin{tabular}{lcc}
\hline Cloud Storage & Rank & Unique Page Views \\
\hline Mediafire & 201 & $149,945,280$ \\
Rapidgator & 580 & $52,434,480$ \\
MEGA & 624 & $49,424,670$ \\
Turbobit & 968 & $31,417,350$ \\
Bitshare & 1,402 & $21,691,860$ \\
Sendspace & 1,858 & $16,368,150$ \\
Freakshare & 2,152 & $14,131,980$ \\
Depositfiles & 2,541 & $12,137,340$ \\
Uploadable & 2,564 & $11,754,690$ \\
Rapidshare & 3,081 & $9,782,220$ \\
\hline
\end{tabular}

Page Views. Traffic data for the study was collected from Alexa and SiteWorthTraffic. A unique page view is defined as a single user viewing a webpage one or more times. A unique visitor is a single user who visits a website one or more times. Unique page views and unique visitors are important measures of website popularity. Cloud storage sites provide this statistical information to advertising companies to encourage them to place ads on their webpages.

Data provided by Alexa and SiteWorthTraffic (as of September 2014) was used to estimate the popularity of cloud storage sites and the number of cloud storage site users. Table 1 presents the estimated unique page views per month for ten major cloud storage sites. The results indicate that Mediafire is the most popular cloud storage site based on Alexa data. Although Mediafire is popular in the United States, the result is unexpected. Upon reflection, it appears that Mediafire's popularity may stem from the fact that it does not remove a download URL unless the associated file is reported as infringing a copyright. As a result, numerous users trust Mediafire and prefer to use it to share normal files; this generates more web traffic at Mediafire than at other cloud storage sites.

Premium Account Revenue. The numbers of registered users and premium account users estimated using Equations (2) and (3), respectively, were used to compute the revenue from premium accounts. Specifically, the equations stipulate that $60.69 \%$ of the unique visitors are registered users and $3 \%$ are premium users. Based on these approximate percentages, the numbers of unique visitors to the targeted cloud storage sites were used to estimate the numbers of registered users and premium users. Table 2 presents the results. In the case of Mediafire, 
Table 2. Estimates of cloud storage site users.

\begin{tabular}{lccc}
\hline Cloud Storage & Unique Visitors & Registered Users & Premium Users \\
\hline Mediafire & $1,666,059$ & $1,666,059$ & 30,333 \\
MEGA & $1,647,489$ & $1,647,489$ & 29,995 \\
Rapidgator & 582,606 & 353,583 & 10,607 \\
Turbobit & 349,082 & 211,857 & 6,355 \\
Bitshare & 241,021 & 146,275 & 4,388 \\
Sendspace & 181,868 & 110,375 & 3,311 \\
Freakshare & 157,022 & 95,296 & 2,858 \\
Depositfiles & 134,859 & 81,845 & 2,455 \\
Uploadable & 130,608 & 79,266 & 2,377 \\
Rapidshare & 108,691 & 65,964 & 1,978 \\
\hline
\end{tabular}

the estimates are 1,666,059 registered users, 30,333 of them premium users.

Table 3. Estimates of monthly revenue from premium users.

\begin{tabular}{lccc}
\hline Cloud Storage & Premium Users & Fee & Revenue \\
\hline MEGA & 29,995 & $\$ 38.86$ & $\$ 1,165,605.70$ \\
Mediafire & 30,333 & $\$ 24.99$ & $\$ 758,021.67$ \\
Rapidshare & 1,978 & $\$ 129.58$ & $\$ 256,309.24$ \\
Rapidgator & 10,607 & $\$ 12.99$ & $\$ 137,784.93$ \\
Sendspace & 3,311 & $\$ 19.99$ & $\$ 66,186.89$ \\
Bitshare & 4,388 & $\$ 9.99$ & $\$ 43,836.12$ \\
Turbobit & 6,355 & $\$ 6.66$ & $\$ 42,324.30$ \\
Uploadable & 2,377 & $\$ 12.99$ & $\$ 30,877.23$ \\
Depositfiles & 2,455 & $\$ 11.95$ & $\$ 29,337.25$ \\
Freakshare & 2,858 & $\$ 9.99$ & $\$ 28,551.42$ \\
\hline
\end{tabular}

Table 3 shows the monthly premium user revenue estimates for ten major cloud storage sites. The monthly subscription fee of each site was used to estimate its monthly revenue. The results indicate that, although only $3 \%$ of the registered users are premium users, significant amounts of revenue are drawn from the users' desire to maintain cloud storage services.

On average, cloud storage sites earn $\$ 255,883.48$ in revenue each month. Because the system architectures of the cloud storage sites are not known, the costs of maintaining their large-scale content distribution networks are not known and it is not clear whether or not their monthly revenues cover their operational costs. Regardless, cloud storage sites cannot rely on premium account subscriptions to maintain sol- 
Table 4. Monthly advertisement revenue estimates.

\begin{tabular}{lcc}
\hline Cloud Storage & Unique Page Views & Ad Revenue \\
\hline Mediafire & $149,945,280$ & $\$ 449,835.84$ \\
Rapidgator & $52,434,480$ & $\$ 157,303.44$ \\
MEGA & $49,424,670$ & $\$ 148,274.01$ \\
Turbobit & $31,417,350$ & $\$ 94,252.05$ \\
Bitshare & $21,691,860$ & $\$ 65,075.58$ \\
Sendspace & $16,368,150$ & $\$ 49,104.45$ \\
Freakshare & $14,131,980$ & $\$ 42,395.94$ \\
Depositfiles & $12,137,340$ & $\$ 36,412.02$ \\
Uploadable & $11,754,690$ & $\$ 35,264.07$ \\
Rapidshare & $9,782,220$ & $\$ 29,346.66$ \\
\hline
\end{tabular}

vency. Clearly, they need other revenue sources to continue to operate, let alone thrive.

Advertisement Revenue Estimates. This section estimates the revenue that a cloud storage site can earn based on unique page views. The advertisement revenue of each cloud storage site is estimated using Equation (1).

Table 4 shows the advertisement revenue estimates of ten major cloud storage sites based on the unique page view data provided by SiteWorthTraffic. Clearly, large numbers of unique page views are important to cloud storage sites. Sites that encourage more user to access their download pages can earn more ad revenue. Additionally, cloud storage sites can cooperate with online advertising companies to collect and analyze user behavior and produce targeted ads. For example, music ads could be displayed when a user accesses an MP3 file download page. In fact, cloud storage sites also monetize the data collected about user behavior by selling it to marketing companies; this can be a substantial and stable source of income. To increase this type of revenue, some cloud storage sites entice users by offering substantial storage space and attractive pay-per-download and premium referral schemes.

Cloud Storage Site Revenue Estimates. Table 5 presents the estimated monthly premium user revenue and monthly advertisement revenue. MEGA earned $\$ 1,313,879.71$ per month or $\$ 15,766,556.52$ annually. MEGA's predecessor, Megaupload, earned about $\$ 175$ million in net income over seven years; in contrast, MEGA's revenue is estimated to be around $\$ 110,383,560$ over seven years. Obviously, MEGA could 
Table 5. Total monthly revenue estimates.

\begin{tabular}{lcccc}
\hline Cloud Storage & Premium Revenue & Ad Revenue & Revenue & Ratio \\
\hline MEGA & $\$ 1,165,605.70$ & $\$ 148,274.01$ & $\$ 1,313,879.71$ & $89 \%$ \\
Mediafire & $\$ 758,021.67$ & $\$ 449,835.84$ & $\$ 1,207,857.51$ & $63 \%$ \\
Rapidgator & $\$ 137,784.93$ & $\$ 157,303.44$ & $\$ 295,088.37$ & $47 \%$ \\
Rapidshare & $\$ 256,309.24$ & $\$ 29,346.66$ & $\$ 285,655.90$ & $90 \%$ \\
Turbobit & $\$ 42,324.30$ & $\$ 94,252.05$ & $\$ 136,576.35$ & $31 \%$ \\
Sendspace & $\$ 66,186.89$ & $\$ 49,104.45$ & $\$ 115,291.34$ & $57 \%$ \\
Bitshare & $\$ 43,836.12$ & $\$ 65,075.58$ & $\$ 108,911.70$ & $40 \%$ \\
Freakshare & $\$ 28,551.42$ & $\$ 42,395.94$ & $\$ 70,947.36$ & $40 \%$ \\
Uploadable & $\$ 30,877.23$ & $\$ 35,264.07$ & $\$ 66,141.30$ & $47 \%$ \\
Depositfiles & $\$ 29,337.25$ & $\$ 36,412.02$ & $\$ 65,749.27$ & $45 \%$ \\
\hline
\end{tabular}

earn much more than Megaupload because it will likely have more users and provide more sophisticated storage services in the near future.

On average, cloud storage sites earn $\$ 366,609.88$ in monthly revenue. Cloud storage sites that cooperate with advertising and marketing companies earn substantially more revenue.

In general, cloud storage sites earn revenue via two methods. The first is by displaying advertisements and selling user behavior data. The second is from free subscriptions. Cloud storage sites encourage frequent visitors to create accounts for additional features, which means more user behavior data can be collected and sold. Also, attractive pay-perdownload schemes encourage uploaders to share files to attract more visitors and potential subscribers. More visitors increases the web traffic and popularity of cloud storage sites, which enable them to earn more ad income and data sales revenue.

As seen in Table 5, most of the revenue comes from premium account subscriptions, with some cloud storage sites (e.g., MEGA and Rapidshare) having more than $89 \%$ of their revenue coming from premium accounts. Premium users generally want much larger storage space, faster download speeds and/or higher pay-per-download rates. Some cloud storage sites also implement referral schemes that provide incentives to premium users when they get other users to sign on to premium accounts. A referral can earn as much as $20 \%$ of the initial subscription fee for the premium service [2]. In summary, this business model makes cloud storage sites one of the most successful and financially-rewarding Internet services. 
Table 6. Monthly revenue estimates for linker sites.

\begin{tabular}{lccc}
\hline Linker Site & Rank & Unique Page Views & Revenue \\
\hline 4shared & 296 & $101,820,960$ & $\$ 305,462.88$ \\
Alluc & 9,739 & $3,094,680$ & $\$ 9,284.04$ \\
Filediva & 31,651 & 974,400 & $\$ 2,923.20$ \\
Filesloop & 39,037 & 900,810 & $\$ 2,702.43$ \\
Keep2Share & 37,508 & 822,240 & $\$ 2,466.72$ \\
Filetram & 43,574 & 697,950 & $\$ 2,093.85$ \\
mega-search.me & 47,763 & 636,720 & $\$ 1,910.16$ \\
Sharedir & 67,156 & 448,800 & $\$ 1,346.40$ \\
Filesdeck & 86,259 & 439,380 & $\$ 1,318.14$ \\
rapid-search-engine & 101,050 & 298,260 & $\$ 894.78$ \\
\hline
\end{tabular}

\subsection{Contributor Revenue}

This section presents the monthly revenue estimates of the contributors in the cloud storage ecosystem.

Linker Site Revenue. Table 6 presents the monthly revenue estimates for ten major linker sites. Note that FilesTube, one of the largest linker sites, recently shut down its search engine; for this reason, FilesTube is not included in the table. The table reveals that 4shared has the largest monthly advertisement revenue, primarily because 4shared is a linker site that also provides traditional cloud storage services. When 4share's revenue is excluded, linker sites have an average monthly advertisement revenue of around $\$ 2,771.08$. The average revenue is considerable because linker sites do not have to implement large file storage systems. All they require is a search engine that collects and provides download links for cloud storage files.

Table \%. Monthly revenue estimates for ad-link shortening sites.

\begin{tabular}{lccc}
\hline Ad-Link Shortening Site & Rank & Unique Page Views & Revenue \\
\hline AdFly & 164 & $189,208,590$ & $\$ 567,625.77$ \\
Linkbucks & 1,035 & $29,798,070$ & $\$ 89,394.21$ \\
Adfoc & 6,661 & $4,565,670$ & $\$ 13,697.01$ \\
Binbox & 7,285 & $4,137,120$ & $\$ 12,411.36$ \\
Shorte.st & 8,593 & $3,589,080$ & $\$ 10,767.24$ \\
\hline
\end{tabular}

Ad-Link Shortening Site Revenue. Table 7 presents the monthly revenue estimates for five major ad-link shortening sites. The data re- 
Table 8. Monthly revenue estimates for multi-upload sites.

\begin{tabular}{lccc}
\hline Multi-Upload Site & Rank & Unique Page Views & Revenue \\
\hline mirrorcreator & 2,381 & $12,952,950$ & $\$ 38,858.85$ \\
embedupload & 9,280 & $3,277,170$ & $\$ 9,831.51$ \\
go4up & 21,247 & $1,431,360$ & $\$ 4,294.08$ \\
mirrorupload & 38,431 & 791,340 & $\$ 2,374.02$ \\
uploadseeds & 48,184 & 625,500 & $\$ 1,876.50$ \\
multfile & 65,647 & 469,800 & $\$ 1,409.40$ \\
uploadmirrors & 66,519 & 457,200 & $\$ 1,371.60$ \\
multiupfile & 82,031 & 361,620 & $\$ 1,084.86$ \\
exoshare & 99,959 & 308,550 & $\$ 925.65$ \\
multiupload.biz & 216,555 & 146,460 & $\$ 439.38$ \\
\hline
\end{tabular}

veals remarkable numbers of unique page views per month. Of particular interest is AdFly. AdFly draws its revenue entirely from advertisements. Still, it earns around $\$ 567,625$ a month, which is more than the revenue that most cloud storage sites earn from premium users.

Multi-Upload Site Revenue. Table 8 presents the monthly revenue estimates for ten major multi-upload sites. The average monthly revenue for the multi-update sites is $\$ 6,246.59$. Compared with the other types of contributors, multi-upload sites have the lowest maintenance costs because they only need to make available the uploading APIs provided by cloud storage sites.

Table 9. Monthly revenue estimates for premium link generator sites.

\begin{tabular}{lccc}
\hline Premium Link Generator & Rank & Unique Page Views & Revenue \\
\hline premiumleech & 48,332 & 629,220 & $\$ 1,887.66$ \\
simply-debrid & 54,750 & 555,480 & $\$ 1,666.44$ \\
generatorlinkpremium & 83,095 & 366,000 & $\$ 1,098.00$ \\
hyperspeeds & 92,910 & 349,650 & $\$ 1,048.95$ \\
Rapid8 & 106,937 & 288,390 & $\$ 865.17$ \\
hungryleech & 116,439 & 261,180 & $\$ 783.54$ \\
premium4.us & 136,060 & 223,170 & $\$ 669.51$ \\
leecher.us & 136,398 & 220,950 & $\$ 662.85$ \\
speedyspeeds & 181,917 & 181,917 & $\$ 545.75$ \\
premium-leechers & 374,287 & 97,470 & $\$ 292.41$ \\
\hline
\end{tabular}

Premium Link Generator Site Revenue. Table 9 presents the monthly revenue estimates for ten major premium link generator sites. The average monthly advertisement revenue for premium link genera- 
tor sites is around \$952.03, which is even lower than that for multiupload sites. Premium link generator sites also gain revenue by using ad-link shortening site services and by encouraging users to provide their cloud storage site premium accounts and subscribe to their paid services. Therefore, the actual monthly revenues for the listed premium link generator sites should be larger than the current estimates.

\section{Discussion}

Increasing numbers of individuals are using cloud storage sites and the cloud storage ecosystem continues to grow. It is common knowledge that most copyright-infringing files are shared via cloud storage sites. This research has shown that cloud storage sites and other entities in the cloud storage ecosystem earn substantial revenue. Criminal entities utilize the ecosystem to make available copyright-infringing files as well as files containing child pornography, or recruiting, planning and coordination information for criminal and terrorist entities. The estimation methods used in this research are useful in web service investigations to assess the revenue earned by the targeted entities based on their web traffic and domain information.

\section{Conclusions}

This chapter has focused on the cloud storage ecosystem and the revenue models of entities in the ecosystem. New contributors, namely ad-link shortening sites, multi-upload sites and premium link generator sites, have joined the ecosystem and share the profits. This chapter has also presented a methodology for estimating the monthly revenues of cloud storage ecosystem entities based on page view traffic and the numbers of unique users. The methodology is especially useful in web service investigations to assess the revenue earned by the targeted entities. The results indicate that cloud storage sites primarily rely on premium account subscriptions and advertising for revenue. The results also suggest that key contributors earn significant revenue even when they merely provide services to support cloud storage.

Future research will examine the relationship between ad-link shortening sites and cloud storage sites. One finding of this study is that ad-link shortening sites earn more revenue that many cloud storage sites and increasing numbers of users are leveraging ad-link shortening sites to share files. Future research will also analyze ad-link shortening links to determine whether or not their popularity stems from the fact that most of the actual links point to cloud storage. 


\section{References}

[1] D. Antoniades, E. Markatos and C. Dovrolis, One-click hosting services: A file-sharing hideout, Proceedings of the Ninth ACM SIGCOMM Conference on Internet Measurement, pp. 223-234, 2009.

[2] S. Arooj, Top 15 websites to earn money by uploading files, Anzaq (www . anzaq. com/2013/07/top-15-websites-to-earn-money-by .html), 2014.

[3] Digital Citizens Alliance, Good Money Gone Bad: Digital Thieves and the Hijacking of the Online Ad Business, Washington, DC (digitalcontentnext.org/wp-content/uploads/2014/ 09/goodmon.pdf), 2014.

[4] Digital Citizens Alliance, Behind the Cyberlocker Door: Cyberlockers Make Millions on Others' Creations, Washington, DC (www.digitalcitizensalliance.org/cac/alliance/ content . aspx?page=cyberlockers), 2016.

[5] Federal Bureau of Investigation, Justice Department charges leaders of Megaupload with widespread online copyright infringement, Press Release, Washington, DC, January 19, 2012.

[6] L. Gannes, Case studies in Freemium: Pandora, Dropbox, Evernote, Automattic and MailChimp, Gigaom, Austin, Texas (gigaom. com/2010/03/26/case-studies-in-freemium-pandora-dropbox -evernote-automattic-and-mailchimp), 2010.

[7] Z. Jelveh and K. Ross, Profiting from filesharing: A measurement study of economic incentives in cyberlockers, Proceedings of the Twelfth IEEE International Conference on Peer-to-Peer Computing, pp. 57-62, 2012.

[8] A. Mahanti, C. Williamson, N. Carlsson, M. Arlitt and A. Mahanti, Characterizing the file hosting ecosystem: A view from the edge, Performance Evaluation, vol. 68(11), pp. 1085-1102, 2011.

[9] J. Moore, Predators and prey: A new ecology of competition, Harvard Business Review, vol. 71(3), pp. 75-83, 1993.

[10] R. O'Neill, Mega outlines 2014 development plans, ZDNet, January $16,2014$.

[11] D. Price, Sizing the Piracy Universe, NetNames, London, United Kingdom (copyrightalliance.org/sites/default/files/2013 -netnames-piracy.pdf), 2013. 
[12] S. Saha, Top 20 highest paying CPM advertising networks 2014, Digital Guide Technology Blog (www.techgyd.com/top-20-high est-paying-cpm-advertising-networks-2014/7405), February $27,2014$.

[13] U.S. Attorney's Office, Eastern District of Virginia, Release for Victim Notification, United States v. Kim Dotcom, et al., Crim. No. 1:12CR3 (E.D. Va. O'Grady, J.), Alexandria, Virginia (www . justice.gov/usao-edva/release-victim-notification), April $22,2015$.

[14] E. Van de Sar, Top 10 largest file-sharing sites, TorrentFreak (torrentfreak.com/top-10-largest-file-sharing-sites-110 828), August 27, 2011. 